\title{
Translation and Validation of the Nepalese Version of Derriford Appearance Scale (DAS59)
}

\author{
Varun Pratap Singh $^{1 *}$, R. K. Singh ${ }^{2}$, T. P. Moss ${ }^{3}$, D. K. Roy ${ }^{4}$ D. D. Baral ${ }^{5}$ \\ ${ }^{1}$ JJT University, Jhunjunu, India; ${ }^{2}$ Department of Prosthodontics, College of Dental Surgery, B.P. Koirala Institute of Health Sciences, \\ Dharan, Nepal; ${ }^{3}$ Department of Psychology, University of the West of England, Bristol, UK; ${ }^{4}$ Dental Surgeon, Dharan, Nepal; \\ ${ }^{5}$ Department of Community Medicine, B.P. Koirala Institute of Health Sciences, Dharan, Nepal. \\ Email: *varundc@gmail.com
}

Received November $23^{\text {rd }}, 2012$; revised December $26^{\text {th }}, 2012$; accepted January $2^{\text {nd }}, 2013$

Copyright (C) 2013 Varun Pratap Singh et al. This is an open access article distributed under the Creative Commons Attribution License, which permits unrestricted use, distribution, and reproduction in any medium, provided the original work is properly cited.

\begin{abstract}
Objectives: To establish a valid and reliable translated version of Derriford Appearance Scale (DAS59) for Nepali population. Methods: A standard translation-back-translation procedure was used followed by evaluation of semantic, conceptual and society equivalence by the committee and changes were made according to recommendations. This corrected version was pretested and a final version was developed. A validation study was performed using the final version on 424 patients including 212 patients with clinical appearance problems and similar number of young adults who had no concern for facial appearance. Reliability was assessed by Cronbach's alpha value and test-retest correlation coefficient. Discriminate and convergent validity were assessed by comparison between clinical and normal population and correlation with Beck's Anxiety Inventory (BAI), Beck's Depression Inventory (BDI) and General Health questionnaire (GHQ). Results: The results indicated excellent internal consistency (Cronbach's alpha $=0.98$ ) and good testretest reliability ( 0.91 for clinical population, 0.86 for normal population). The Discriminate validity was good with statistically significant differences between clinical and normal population. The convergent validity was confirmed by good correlation with other related psychometric tools. Conclusion: A valid and reliable Nepali DAS59 version was developed which can be used for research and clinical assessment of patients with appearance problems and concerns.
\end{abstract}

Keywords: Derriford Appearance Scale; Reliability; Translation; Validation

\section{Introduction}

Attractiveness is a visual cue that people use to make assumptions and conclusions about the personality and behavior of others in once-off encounters and it can influence how we treat other. In modern society, physical beauty is perceived as a personal characteristic and is valued as such in its own right, independent of other traits [1]. The general consensus is that attractiveness does impact upon how others perceive individuals, such that attractive individuals are associated with more positive social attributes and characteristics. It appears from the literature that society judges an individual's personal characteristics from their outward appearance at a very young age. An individual's physical appearance is associated with their inward character so that what is beautiful on the outside is also perceived to be beautiful on the

\footnotetext{
"Corresponding author.
}

inside. The "beautiful equals good" stereotype prevails [2-7].

Disfigurement and deformity is associated with negative social and psychological effects [8-11]. The psychological aspects of a deformity should not be underestimated, daily social interactions for those with problems of appearance is a source of unremitting stress, anxiety and anguish, all of which have implications for personality functioning and mental health [11]. Individuals often have to endure negative social reactions from other members of the public ranging from stares and whispers to ridicule and alienation, with the result that they are socially disadvantaged and can be psychologically damaged. As a result one of the most common responses of individuals with disfigurement is to withdraw from social interaction [12]. Appearance problems are often associated with an altered self-image, and decreased self-esteem [13-15]. 
As appearance problems and concerns have shown to be associated with psychological, psychosocial problems and adjustments, it is very important to assess the psychological distress and psychological adjustment in subjects with appearance concerns. Further it could be useful in case of surgical procedure to assess changes pre and postoperatively [16]. There are various psychometric tools available to measure psychological impact and adjustment of appearance such as the Appearance Schemas Inventory [17], the Body Image Avoidance Questionnaire [18] and the Body Dysmorphic Disorder Examination [19], but they suffer from low content validity, restricted range of applicability, impracticability or limited psychometric development. None of these measures were designed specifically to assess the spectrum of symptomatology that is relevant to the wide range of difficulties experienced by patients living with problems of appearance; therefore, the scales lack sensitivity to the nature of the dysfunctions and the severity of the distress that these patients experience [16].

The Derriford Appearance Scale was specifically designed for measuring the psychosocial adjustment in patients with appearance problem. This scale had demonstrated excellent reliability and validity and had been used in general population with no appearance concern, general population with appearance concern and clinical population with appearance problems. There are two versions of scale-a short version which consists of 24 items basically meant for routine use in clinical practice and a elaborate 59 item version meant for research and detailed assessment [20-22]. This scale had demonstrated excellent psychometric properties when translated and validated internationally [23,24]. Before applying any psychometric tool to different ethnic population settings it should be translated, validated and adapted according to local cultural and social needs. Therefore the aim of this study was to develop a valid and reliable Nepalese version of Derriford appearance sacle (DAS59).

\section{Materials and Methods}

\subsection{Translation of DAS59}

The DAS59 is copyright protected and translation procedure to be followed is listed in the website. First of all permission is taken regarding translation from the developer then the tool was subjected to conceptual, semantic and society equivalence. This was done by a committee comprising of a clinical psychologist, orthodontist, general surgeon, Public health specialist, members of the civil society and members of the target population. The committee suggested following changes: 1) Change the options in the question "your ethnic background" as Nepal has different ethnicity than UK; 2) To add religion also, because many religious practices are so unique here that it can affect the outcome; 3) To include
Caste also according to demographics of Nepal; 4) Question 37 refers to the beach, Nepal is a land-lock country with no seashores, and instead we replaced it by swimming. However there was a repeat [HOW DISTRESSED DO YOU GET WHEN, item 37 You go to swim (as modified from you go to the beach)], [HOW DISTRESSED ARE YOU BY, item 45 Not being able to go swimming], but the committee that both sections are different and a repeat can be justified, as the meaning of the question changes in both sections, first section, says about self consciousness because of swimwear. Second section emphasize on the stress which he/she gets when he/she is not able to go to swimming due to his/her "feature", whereas many of his/her friends are going for swimming.

Then a discussion was organized with the committee members and members of the target population. The replacement item were then finalized and communicated to the developer of the scale for approval, later with the consent of developer new items were included.

We followed the standard translation-back translation procedure as mentioned by the developer with translation by an individual whose first language is English but has good knowledge and command of Nepali language, facilitated by the fact that Dharan, Nepal is the hub of British Gurkhas and as many of them are settled in UK from generations. We could find such people whose first language is English and they well versed with Nepali too because of their Nepali origin. Two individuals did translation independently and then it was synthesized by a third translator. Now the translated version was back translated by two individuals independently whose first language is Nepali, but they are well versed in English, we selected three English language teachers from various Arts colleges. Two of them did the back translation independently and third synthesized it into one version. This version was compared with original translation for conceptual and semantic equivalence and with discussion with committee members, translators the final version was made. This final version was then pretested in the target population, two interviewers-one orthodontist and clinical psychologist administered the questionnaire to 50 individuals from both the groups. We asked each individual to read each item and try to explain the interviewer about their interpretation of that question. There were no confusing items and the subjects were readily able to understand all items and the final Nepali version was ready.

\subsection{Administration of the Nepali Version of DAS59}

\subsubsection{Derriford Appearance Scale (DAS59)}

The DAS59 is presented as a series of 59 statements and questions with response categories in a Likert format to 
measure frequency of symptomatology (“almost never” ... "almost always") and levels of associated distress ("not at all distressed" ... "extremely distressed"). An introductory section gathers relevant demographic information and identifies the aspect of appearance that is of greatest concern to the respondent. This is referred to as the respondent's "feature" in the body of the scale. It also identifies any other aspects of appearance about which the respondent may also be concerned. Fifty-seven items assess relevant psychological distress and dysfunction, and two items assess physical distress and physical dysfunction. The format of the introductory section and a "not applicable" response category for most items make the scale acceptable to respondents who are not concerned about appearance such as those in the general population.

Actually clear and concise instructions are given on how to complete the scale, which is designed as a selfreport questionnaire to be completed without supervision but in this study subjects were asked to complete the questionnaire in the presence of administrator, however the administrator did not interfere with privacy of the patient. The DAS59 generates six measures of psychological distress and dysfunction (an overall, full-scale score and five factorial scores) as well as a measure of physical distress and dysfunction (items 25 and 26). The five domains are 1) General self-consciousness of appearance (GSC); 2) Social self-consciousness of appearance (SSC); 3) Sexual and body self-consciousness of appearance (SBSC); 4) Negative Self concept (NSC); 5) Facial self-consciousness of appearance (FSC) [25].

General Health Questionnaire (GHQ12): This is a 12 items scales that is used to asses mental health status especially in detection of emotional disorders such as distress. The scoring is done on a likert scale. The translated and validated Nepali version is available [26].

Beck's Anxiety Inventory (BAI) and Beck's Depression Inventory (BDI): These 21 items scales are used to assess depression and anxiety symptoms. Items are scored on a likert scale. The translated and validated Nepali version is available $[27,28]$.

\subsubsection{Sample Size Calculation}

The sample size of internal consistency for the Cronbach's alpha was calculated by using Bonnett's Formula [29] with an alpha of 0.05 and a power of $90 \%$, a sample size of 133 subjects would be required. In order to allow a $10 \%$ missing data rate at least 146 subjects should be invited.

Ethical clearance was obtained from Institutional ethical review board and guidelines from declaration of Helsinki were followed.

\subsubsection{Clinical Sample}

Adult patients with appearance problems were identified from hospital record comprising developmental or acquired disfigurement, these included craniofacial disfigurement (both developmental and acquired), post traumatic scarring, post burn scarring, mastectomy patients reporting for secondary treatment due to appearance concern. We were able to retrieve records of 300 patients aged between 18 - 29 (Mean $23.08 \pm 1.69$ ). All were invited for the study; of these two hundred twelve (70\%) agreed to participate in the study. There were $111 \mathrm{fe}$ males and 101 males.

\subsubsection{Non Clinical Sample}

Similar numbers of young adults between 18 - 29 (Mean $23.13 \pm 2$ ) years of age were recruited conveniently from Dharan municipality, Dharan City, Nepal who were not concern about their appearance. There were 112 males and 100 females. In this way a total of 424 patients were asked to complete the questionnaire in the calm university hospital settings in the presence of one investigator who did not interfere with the privacy of the patient. There were 211 females and 213 males. Out of total 50 patients were selected randomly for test-retest analysis from each group.

The questionnaire consisted of

1) Nepali version of DAS consisting of 59 items. Each item response is marked based on a four point likert scale from 1 to 4 with 1 indicating "almost never" and 4 indicate "almost always".

2) General Health Questionnaire (GHQ12) consisting of 12 items. Each item response is marked based on a four point likert scale from 1 to 4 with 1 indicating "not at all" and 4-"much more than usual". A validated Nepali Version was available and was used.

3) Beck's Anxiety Inventory (BAI) and Beck's Depression Inventory (BDI): Consisting of 21 items each. In BAI each item response is marked based on a four point likert scale from 1 to 4 with 1 indicating "not at all” and 4-“severely, I could barely stand it”. In BDI each item response is marked based on a four point likert scale from 1 to 4 . Validated Nepali versions were available and were used.

\section{Statistical Analysis}

The data was entered in SPSS Version 19. Reliability of the scale was tested by Cronbach's alpha coefficient and coefficient of correlation. The retest reliability was also tested using Spearman's correlation coefficient between items and scale total score.

Discriminant validity was tested by assessing the differences between those who are not concerned about facial appearance and those who seek treatment for problems of appearance using Mann-Whitney test. Convergent validity was tested by assessing the correlation between DAS59 with GHQ12, BDI and BAI scales. 


\section{Results}

Reliability: The scale demonstrated good reliability and internal consistency as shown by overall Cronbach's alpha value of 0.985 and corrected inter-item correlation values between 0.57 to 0.81 . The Cronbach's alpha if item deleted showed that deleting an item will not increase the Cronbach's alpha hence all the items to be retained. Domain wise, the Cronbach's alpha of 0.95 , $0.95,0.90,0.88,0.85$ respectively with corrected interclass coefficient ranging from 0.53 to $0.85,0.60$ to 0.77 , 0.57 to $0.76,0.55$ to 0.81 and 0.64 to 0.72 respectively (Table 1).

\subsection{Test-Retest Reliability}

The scale total test-retest correlation coefficient was 0.91 for clinical population and 0.86 for the normal population not concerned about appearance.

\subsection{Validity}

\section{Face and Content Validity}

Face validity was good as confirmed by the expert committee consisting of orthodontist, clinical psychologist; epidemiology expert and members of the target population; further review of literature also confirmed the face validity.

Discriminant validity was confirmed by the significant differences between the subjects with no concern for appearance and those with reported problems of appearance (Table 2). Convergent validity was confirmed by significant correlation between this scale and BDI, BAI, GHQ12 scales. (The correlation coefficient ranged from 0.69 to 0.76 ) (Table 3).

\section{Discussion}

This study describes the translation and validation of DAS59 into Nepali. The translation procedure is already

Table 1. Shows no of items in each domain along with Cronbach's alpha if item deleted and corrected inter class correlation between the domains [ $\left.{ }^{*} 1\right)$ General self-consciousness of appearance (GSC); 2) Social self-consciousness of appearance (SSC); 3) Sexual and body self-consciousness of appearance (SBSC); 4) Negative Self concept (NSC); 5) Facial self-consciousness of appearance (FSC)].

\begin{tabular}{cccc}
\hline Domain & $\begin{array}{c}\text { No. of } \\
\text { items }\end{array}$ & $\begin{array}{c}\text { Cronbach’s } \\
\text { alpha }\end{array}$ & $\begin{array}{c}\text { Corrected item- } \\
\text { total correlation }\end{array}$ \\
\hline GSC & 17 & 0.95 & 0.53 to 0.85 \\
SSC $^{*}$ & 20 & 0.95 & 0.60 to 0.72 \\
SBSC $^{*}$ & 09 & 0.90 & 0.57 to 0.76 \\
NSC $^{*}$ & 05 & 0.88 & 0.55 to 0.81 \\
FSC $^{*}$ & 04 & 0.85 & 0.64 to 0.72 \\
\hline
\end{tabular}

Table 2. Differences between domains, main scale and other scales against grouping variables-patients who are not concerned about their appearance and those with appearance problems by using Mann-Whitney U Test.

\begin{tabular}{ccc}
\hline Scale and domains & Mann-Whitney U & Asymp. sig. (2-tailed) \\
\hline DAS59 & 567.00 & $0.000^{*}$ \\
GSC & 955.500 & $0.000^{*}$ \\
SSC & 550.00 & $0.000^{*}$ \\
SBSC & 1393.500 & $0.000^{*}$ \\
NSC & 984.00 & $0.000^{*}$ \\
FSC & 614.00 & $0.000^{*}$ \\
PHY & 2818.00 & $0.000^{*}$ \\
OTH & 2953.00 & $0.000^{*}$ \\
BDI & 480.500 & $0.000^{*}$ \\
BAI & 784.00 & $0.000^{*}$ \\
GHQ & 1291.00 & $0.000^{*}$
\end{tabular}

*Correlation is significant at the 0.001 level.

Table 3. Showing significant correlation between DAS59, BDI, BAI and GHQ12.

\begin{tabular}{|c|c|c|c|c|c|c|}
\hline & & & Total & BDI & BAI & GHQ \\
\hline \multirow{6}{*}{$\begin{array}{c}\text { Spearman's } \\
\text { rho }\end{array}$} & \multirow{2}{*}{ DAS59 } & $\begin{array}{l}\text { Correlation } \\
\text { coefficient }\end{array}$ & 1.000 & 0.760 & 0.731 & $0.748^{* *}$ \\
\hline & & Sig (2-tailed) & - & 0.000 & 0.000 & 0.000 \\
\hline & \multirow{2}{*}{ BDI } & $\begin{array}{l}\text { Correlation } \\
\text { coefficient }\end{array}$ & 0.760 & 1.00 & 0.762 & $0.693^{* *}$ \\
\hline & & Sig (2-tailed) & 0.000 & 0.000 & 0.000 & 0.000 \\
\hline & \multirow{2}{*}{ GHQ } & $\begin{array}{l}\text { Correlation } \\
\text { coefficient }\end{array}$ & 0.748 & 0.693 & 0.698 & 1.000 \\
\hline & & Sig (2-tailed) & 0.000 & 0.000 & 0.000 & 0.000 \\
\hline
\end{tabular}

${ }^{* *}$ Correlation is significant at the 0.001 level.

explained in detail in the methodology section. The overall internal consistency was excellent $(\alpha=0.98)$ and was equal to that of the original article that first described the scale [16]. There was good correlation between all the items representing a good homogeneity. Domains also demonstrated good internal consistency and correlation within themselves. The test-retest reliability was also good.

The Construct validity of the Nepali DAS59 was assessed under convergent and Discriminant validity. Discriminant validity was demonstrated by highly significant differences between the clinical population having appearance concern and nonclinical population with no facial concern. Convergent validity was confirmed by significant correlation between DAS59, BDI, BAI and GHQ. 


\section{Conclusion}

A reliable and valid Nepali version of DAS59 was developed to measure the psychological impact and adjustment for use in subjects with problems of appearance.

\section{Acknowledgements}

The authors thank Mr. David Harris and Mr. Tony Carr whose ideas lead to the development of the Derriford Appearance Scale. The authors thank Dr. Brandon Kohrt for his valuable help in providing translated and validated Nepali versions of GHQ-12, BDI, BAI. Further the authors acknowledge Dr. D.D. Agarwal, Hon. Vicechancellor, JJT University and Dr. Om Prakash of the same university for their valuable suggestions.

\section{REFERENCES}

[1] M. T. Hilhorst, "Physical Beauty: Only Skin Deep?” Medicine, Health Care and Philosophy, Vol. 5, No. 1, 2002, pp. 11-21. doi:10.1023/A:1014217922801

[2] K. Dion, E. Berscheid and E. Walster, "What Is Beautiful Is Good," Journal of Personality and Social Psychology, Vol. 24, No. 3, 1972, pp. 285-290. doi:10.1037/h0033731

[3] K. K. Dion, "Physical Attractiveness and Evaluation of Children's Transgressions," Journal of Personality and Social Psychology, Vol. 24, No. 2, 1972, pp. 207-213. doi:10.1037/h0033372

[4] E. Walster, V. Aronson, D. Abrahams and L. Rottman, "Importance of Physical Attractiveness in Dating Behavior,” Journal of Personality and Social Psychology, Vol. 4, No. 5, 1966, pp. 508-516. doi:10.1037/h0021188

[5] W. C. Shaw, "Factors Influencing the Desire for Orthodontic Treatment," European Journal of Orthodontics, Vol. 3, No. 3, 1981, pp. 151-162.

[6] W. C. Shaw, G. Rees, M. Dawe and C. R. Charles, "The Influence of Dentofacial Appearance on the Social Attractiveness of Young Adults," American Journal of Orthodontics, Vol. 87, No. 1, 1985, pp. 21-26. doi:10.1016/0002-9416(85)90170-8

[7] S. J. Cunningham, "The Psychology of Facial Appearance," Dental Update, Vol. 26, No. 10, 1999, pp. 438444.

[8] C. Philips, M. E. Bennett and H. L. Broder, "Dentofacial Disharmony: Psychological Status of Patients Seeking a Treatment Consultation," The Angle Orthodontist, Vol. 68, No. 6, 1998, pp. 547-556.

[9] H. L. Broder, C. Phillips and S. Kaminetzky, "Issues in Decision Making: Should I Have Orthognathic Surgery?” Seminars in Orthodontics, Vol. 6, No. 4, 2000, pp. 249258. doi:10.1053/sodo.2000.19073

[10] F. C. Macgregor, "Social and Psychological Implications of Dentofacial Disfigurement," The Angle Orthodontist, Vol. 40, No. 3, 1970, pp. 231-233.

[11] F. C. Macgregor, "Facial Disfigurement: Problems and Management of Social Interaction and Implications for Mental Health,” Aesthetic Plastic Surgery, Vol. 14, No. 1,
1990, pp. 249-257. doi:10.1007/BF01578358

[12] H. W. Neale, D. A. Billmire and J. P. Carey, "Reconstruction Following Head and Neck Burns," Clinical Plastic Surgery, Vol. 13, No. 1, 1986, pp. 119-136.

[13] E. E. Williams and T. A. Griffiths, "Psychological Consequences of Burn Injury,” Burns, Vol. 17, No. 6, 1991, pp. 478-480.

[14] E. Stice and H. E. Shaw, "Role of Body Dissatisfaction in the Onset and Maintenance of Eating Pathology: A Synthesis of Research Findings," Journal of Psychosomatic Research, Vol. 53, No. 5, 2002, pp. 985-993. doi:10.1016/S0022-3999(02)00488-9

[15] B. Verplanken and R. Velsivik, "Habitual Negative Body Image Thinking as Psychological Risk Factor in Adolescents,” Body Image, Vol. 5, No. 2, 2008, pp. 133-140. doi:10.1016/j.bodyim.2007.11.001

[16] T. Carr, D. Harris and C. James, "The Derriford Appearance Scale (DAS-59): A New Scale to Measure Individual Responses to Living with Problems of Appearance," British Journal of Health Psychology, Vol. 5, No. 2, 2000, pp. 201-215. doi:10.1348/135910700168865

[17] T. F. Cash and A. S. Labarage, "Development of Appearance Schemas Inventory: A New Cognitive BodyImage Assessment," Cognitive Therapy and Research, Vol. 20, No. 1, 1996, pp. 37-50. doi:10.1007/BF02229242

[18] J. C. Rosen, D. Srebnik, E. Saltzburg and S. Wendt, "Development of a Body Image Avoidance Questionnaire," Psychological Assessment: Journal of Consulting and Clinical Psychology, Vol. 3, No. 3, 1991, pp. 32-37.

[19] J. Rosen, J. Reiter and P. Osoran, "Cognitive-Behavioral Body Image Therapy for Body Dysmorphic Disorder," Journal of Consulting and Clinical Psychology, Vol. 63, No. 2, 1995, pp. 263-269. doi:10.1037/0022-006X.63.2.263

[20] D. L. Harris and A. T. Carr, "The Derriford Appearance Scale (DAS59): A New Psychometric Scale for the Evaluation of Patients with Disfigurements and Aesthetic Problems of Appearance," British Journal of Plastic Surgery, Vol. 54, No. 3, 2001, pp. 216-222. doi:10.1054/bjps.2001.3559

[21] T. P. Moss, P. White, S. Newman and H. James, "Factor Analysis of the DAS24: Conceptual and Statistical Issues,” Presented at Appearance Matters 4 Conference, Bristol, 2010.

[22] T. Carr, T. Moss and D. Harris, "The DAS24: A Short Form of the Derriford Appearance Scale (DAS59) to Measure Individual Responses to Living with Problems of Appearance," British Journal of Health Psychology, Vol. 10, No. 2, 2005, pp. 285-298. doi:10.1348/135910705X27613

[23] N. Keiko, H. Kazuhiro, N. Nobuaki, N. Reiko, I. Katsunori, I. Nobuak, T. P. Moss and D. L. Harris, "Development of the Japanese Version of Derriford Appearance Scale DAS59: A QOL Index for the People Who Have Problems of Appearance," Journal of Japan Society of Plastic and Reconstructive Surgery, Vol. 28, No. 7, 2008, pp. 440-448.

[24] T. B. Won, K. T. Park, S. J. Moon, I. J. Moon, J. H. Wee, 
T. Moss and H. R. Jin, "The Effect of Septorhinoplasty on Quality of Life and Nasal Function in Asians,” Annals of Plastic Surgery, 2012. doi:10.1097/SAP.0b013e3182414641

[25] D. Harris, T. P. Moss and T. Carr, "Manual for the Derriford Appearance Scale 59 (DAS59),” Musketeer Press, Bradford on Avon, 2004.

[26] N. R. Koirala, S. K. Regmi, V. D. Sharma, A. Khalid and M. K. Nepal, "Sensitivity and Validity of the General Health Questionnaire-12 in a Rural Community Settings in Nepal," Nepalese Journal of Psychiatry, Vol. 1, No. 1, 1999, pp. 34-40.

[27] B. A. Kohrt, R. D. Kunz, N. R. Koirala, V. D. Sharma and M. K. Nepal, "Validation of a Nepali Version of the Beck Depression Inventory," Nepalese Journal of Psychiatry, Vol. 2, No. 4, 2002, pp. 123-130.

[28] B. A. Kohrt, R. D. Kunz, N. R. Koirala, V. D. Sharma and M. K. Nepal, "Validation of a Nepali Version of the Beck Anxiety Inventory,” Nepalese Journal of Psychiatry, Vol. 25, No. 1, 2003, pp. 1-4.

[29] K. Peker, O. Uysal and G. Bermek, "Cross Cultural Adaptation and Preliminary Validation of the Turkish Version of the Early Childhood Oral Health Impact Scale among 5 - 6-Year-Old Children," Health and Quality of Life Outcomes, Vol. 9, 2011, p. 118. doi:10.1186/1477-7525-9-118 